\title{
Editorial for current state of intraoperative imaging in spinal surgery
}

This series of Annals of Translational Medicine presents a collection of review articles on the current state of intraoperative imaging in spinal surgery. The rates of spine surgery and spinal instrumentation have increased tremendously in the past two decades. This increase has been accompanied by technological innovations and advances that are expanding the horizon of spinal surgery and making these procedures increasingly feasible, safe and efficient for the management of a wide range of disorders.

Intraoperative image-guidance in particular has undergone tremendous advancements in recent years, evolving from two-dimensional imaging modalities such as $2 \mathrm{D}$ fluoroscopy or serial radiography to computer assisted navigation systems that provide real-time visualization of instrumentation on a three-dimensional map of the patient's anatomy in order to provide better visualization and increase accuracy, and more recently the integration of these navigation systems with robotics with the goal of improving dexterity, reducing fatigue and dampening physiological tremor, thereby improving accuracy and precision, as well as the adaptation of augmented reality and virtual reality in spinal surgery to improve operative and teaching experiences.

Given the rapid rate of evolution of these technologies as well as the wide variability in surgical procedures and surgical techniques for spinal surgery, this series aims to provide an in-depth and consolidated review of the numerous intraoperative imaging modalities available as they relate to various types of spinal surgery.

We are extremely thankful to all the authors for their invaluable contributions to this series. We hope you find these reviews to be interesting and educational. We believe this series will not only provide clinically relevant information to surgeons, but will also serve as the foundation for future research.

\section{Acknowledgments}

Funding: None.

\section{Footnote}

Provenance and Peer Review: This article was commissioned by the editorial office, Annals of Translational Medicine, for the series "Current State of Intraoperative Imaging". The article did not undergo external peer review.

Conflicts of Interest: The author has completed the ICMJE uniform disclosure form (available at http://dx.doi.org/10.21037/ atm-2020-ioi-12). The series "Current State of Intraoperative Imaging” was commissioned by the editorial office without any funding or sponsorship. SQ served as the unpaid Guest Editor of the series and serves as an unpaid editorial board member of Annals of Translational Medicine from Sep 2019 to Aug 2021. SQ reports other from Cervical Spine Research Society, personal fees from Stryker K2M, other from Simplify Medical, Inc., other from Avaz Surgical, other from International Society for the Advancement of Spine Surgery, other from North American Spine Society, other from LifeLink.com Inc., other from Association of Bone and Joint Surgeons, other from Society of Lateral Access Surgery, personal fees from Globus Medical, Inc. , personal fees from Paradigm Spine, other from Society of Minimally Invasive Spine Surgery, other from Minimally Invasive Spine Study Group, personal fees from RTI Surgical Inc., other from Spinal Simplicity, LLC, personal fees from AMOpportunities, other from Contemporary Spine Surgery, other from Annals of Translational Medicine, personal fees from Healthgrades, other from The American Orthopaedic Association, other from Vital 5, outside the submitted work.

Ethical Statement: The author is accountable for all aspects of the work in ensuring that questions related to the accuracy or integrity of any part of the work are appropriately investigated and resolved.

Open Access Statement: This is an Open Access article distributed in accordance with the Creative Commons Attribution- 
NonCommercial-NoDerivs 4.0 International License (CC BY-NC-ND 4.0), which permits the non-commercial replication and distribution of the article with the strict proviso that no changes or edits are made and the original work is properly cited (including links to both the formal publication through the relevant DOI and the license). See: https://creativecommons.org/ licenses/by-nc-nd/4.0/.

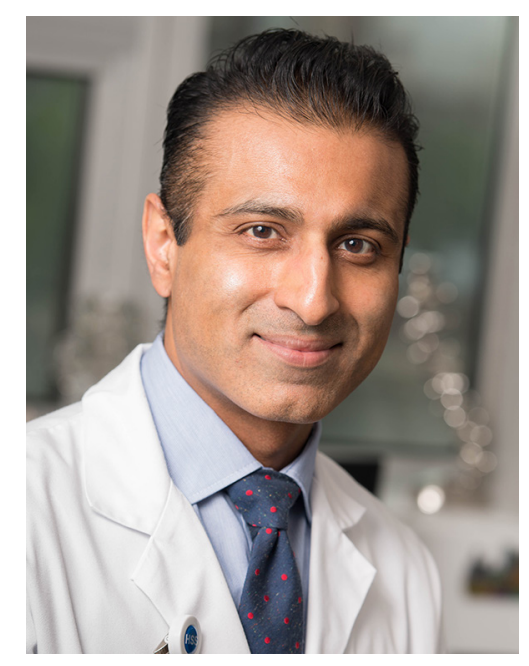

Sheeraz Qureshi

Sheeraz Qureshi

Department of Orthopedic Surgery, Hospital for Special Surgery, New York, NY, USA.

(Email: qureshis@bss.edu)

Submitted Dec 05, 2020. Accepted for publication Dec 18, 2020. doi: 10.21037/atm-2020-ioi-12

View this article at: http://dx.doi.org/10.21037/atm-2020-ioi-12

Cite this article as: Qureshi S. Editorial for current state of intraoperative imaging in spinal surgery. Ann Transl Med 2021;9(1):83. doi: 10.21037/atm-2020-ioi-12 